\title{
EFFECT OF BEAN RUST [UROMYCES APPENDICULATUS (PERS.) STRAUSS] ON PHOTOSYNTHETIC CHARACTERISTICS, SUPEROXIDE-DISMUTASE ACTIVITY, AND LIPID PEROXIDATION OF COMMON BEAN (PHASEOLUS VULGARIS L.)
}

\author{
Cs. BoJTOR ${ }^{\mathrm{a}}$, Z. GYŐRI ${ }^{\mathrm{a}}$, P. SIPOS ${ }^{\mathrm{a}}$, L. RADÓCZ ${ }^{\mathrm{b}}$ and B. Tóth ${ }^{\mathrm{a}}{ }^{*}$ \\ ${ }^{a}$ Institute of Nutrition, University of Debrecen, H-4032 Debrecen, Egyetem tér 1. Hungary \\ ${ }^{\mathrm{b}}$ Institute of Plant Protection, Faculty of Agricultural and Food Sciences and Environmental Management, \\ University of Debrecen, H-4032 Debrecen, Böszörményi út 138. Hungary \\ ${ }^{\S}$ Present address: Institute of Plant Sciences (Plant Breeding), Faculty of Natural and Agricultural Sciences, \\ University of the Free State, PO Box 339, Bloemfontein 9300. Republic of South Africa
}

(Received: 24 August 2018; accepted: 1 November 2018)

\begin{abstract}
The aim of the study was to investigate changes of photosynthetic efficiency, amount of photosynthetic pigments, superoxide dismutase (SOD) enzyme activity, and rate of lipid peroxidation in bean-rust interaction. The clarification of the role of the above changes involved in the defence mechanism can significantly contribute to the breeding of plant varieties with natural resistance. Consequently, the amount of chemicals used in food production can be significantly reduced. In the present study some principal physiological parameters, such as the relative chlorophyll content of the host plant, the amount of photosynthetic pigments, changes in photosynthetic efficiency, and the activity of superoxide-dismutase (SOD) in addition to rate of lipid peroxidation (LP) were measured. The experiment was conducted in a humidity tent. Significant decrease in the relative chlorophyll content and in the amount of photosynthetic pigments was measured. At both sampling times, an increase was found in superoxide-dismutase enzyme activity and in rate of lipid peroxidation due to the bean rust infection. Notably, in several cases the differences were significant. The results indicate that the above parameters have important role in the bean-rust interaction, which should be taken into consideration in resistance breeding.
\end{abstract}

Keywords: bean rust, chlorophyll, common bean, lipid peroxidation, superoxide-dismutase

Numerous stress factors affect the development of plants. These factors can be divided into two categories, namely biotic and abiotic. Various studies indicated that biotic stress factors, such as diverse pathogens, have an impact on the natural defence mechanism of plants (ShetTy et al., 2008; BARNA et al., 2012). Oxidative stress is regarded as a central factor in abiotic and biotic stress phenomena, which occurs when a serious imbalance exists in any compartment between the production of reactive oxygen species (ROS) and antioxidant defence, leading to dramatic physiological challenges (FOYER \& NOCTOR, 2003). Furthermore, SHETTY and co-workers (2008) proved that various infections have an increasing effect on the amount of reactive oxygen species (ROS) in the tissues. The latter seemed to have an adverse effect on lipids, proteins, and nucleic acids.

The social value of the common bean is considerably high to millions of people in many countries especially in Latin America, Eastern and Southern Africa, as well as in Europe (Broughton et al., 2003). Moreover, bean rust, caused by Uromyces appendiculatus, is responsible for major production problems on a universal scale (STAVEly \& PASTOR-CorRales, 1989).

\footnotetext{
* To whom corrwapondence should be addressed.

Phone: +36 30273 8842; e-mail: btoth@agr.unideb.hu
} 
As the development of diseases is the result of a compatible interaction between host, pathogen, and environment, its dynamics depends on the suitability of each component either to favour or disfavour the epidemic process (AgRIos, 2005). The two major opponents, the host and the pathogen, given optimal environmental favourability and absence of human intervention, influence each other and determine not only the course of the resulting epidemic, but also host growth dynamics and yield (Mersha \& HAU, 2011). Among the most destructive diseases that attack common bean causing serious problems, bean rust is regarded as the most prevalent. The latter is incited by a highly variable pathogen, namely the fungus, Uromyces appendiculatus (Pers.) Strauss. Worldwide losses, measured in greenhouse and field conditions, can vary from 18 to $100 \%$ (Stavely \& Pastor-Corrales, 1989). Disease management practices for bean rust control include crop rotation, soil incorporation of bean debris, planting within recommended dates, growing resistant cultivars, and timely spraying of fungicides (MmBaGa et al., 1996).

Common bean is a highly polymorphic species showing considerable variation in growth habit depending on cultivar and environment. The pathogen $U$. appendiculatus is an obligate, biotrophic, autoecious, and macrocyclic fungus (McMillan et al., 2003). The development of bean rust is highly influenced by environmental factors, such as temperature and humidity, and host factors. Repeated disease cycles may occur at 10 to 14 day intervals under favourable conditions (Stavely \& Pastor-Corrales, 1989).

Biotic stress usually stimulates the production of reactive oxygen species (ROS), such as the superoxide anion $\left(\mathrm{O}^{-2}\right)$, hydrogen peroxide $\left(\mathrm{H}_{2} \mathrm{O}_{2}\right)$, and hydroxyl radicals (Suzuki \& MitTLER, 2006).

Therefore, the main objective of the study was to clarify the physiological changes generated in the host-pathogen interaction, which could enhance the understanding of the underlying processes of the sensibility and resistance mechanisms of the plants. Secondary aims, which resulted from the investigation included the investigation of the process which contributed to the level of important enzymes related to the ROS molecules changes in the host-pathogen interaction. Consequently, these results led to the development of common bean cultivars possessing a natural resistance to bean rust.

\section{Materials and methods}

\subsection{Basic parameters of the experiments}

In this experiment, the effect of the bean rust [Uromyces appendiculatus (Pers.) Strauss] infection was investigated on both the physiological parameters of the key plant and the enzyme activities of the host plant (Phaseolus vulgaris L. cv. Sonesta). Bean plants were artificially inoculated with a suspension of Uromyces appendiculatus (Pers.) Strauss. The experiments were conducted in a humidity tent. A 2:1 mixture of chernozem soil and peat was used as a growing medium for the optimal germination and initial development of the plants. Samples were taken seven and 14 days after inoculation. Among the physiological parameters of the key plant, the relative chlorophyll content, the exact amount of photosynthetic pigments, and the light stage efficiency of photosynthesis were measured. Furthermore, among the enzyme activities, the activity of superoxide dismutase (SOD) and the rate of lipid peroxidation (LP) were examined. 


\subsection{Quantification of photosynthetic pigments}

First, for the measurement of the changes in the relative chlorophyll content, the primary leaves of the plants were used. The measurement was done with a SPAD-502 (Minolta, Japan) chlorophyll meter (UdDLing et al., 2007).

In addition, the exact quantification of the photosynthetic pigments (chlorophyll- $a,-b$, and carotenoids) was obtained in the experiment. The exact amount of these pigments was measured with a Metertech SP 80 Spectrometer using the method of MoRAN and PORATH (1980) and calculated based on WellBurn (1994). Firstly, a $50 \mathrm{mg}$ fresh sample taken from the primary leaves of the plants was dissolved in $5 \mathrm{ml} \mathrm{N}, \mathrm{N}$-dimethylformamide at $4{ }^{\circ} \mathrm{C}$ for $72 \mathrm{~h}$. After $72 \mathrm{~h}$, the quantity of the chlorophyll- $a$ was measured at $664 \mathrm{~nm}$, the chlorophyll- $b$ at $647 \mathrm{~nm}$, and the carotenoids at $480 \mathrm{~nm}$.

The amount of photosynthetic pigments $\left(\mathrm{mg} \mathrm{g}^{-1}\right)$ can be calculated by using the method of Moran and Porath (1980). The fresh weight of the samples was used to complete the following equations:

$$
\begin{aligned}
\text { chlorophyll- } a & =(11.65 \times \mathrm{a} 664-2.69 \times \mathrm{b} 647) \\
\text { chlorophyll }-b & =(20.81 \times \mathrm{b} 647-4.53 \times \mathrm{a} 664) \\
\text { carotenoids } & =(1000 \times \text { car } 480-1.28 \times \mathrm{a} 664-56.7 \times \mathrm{b} 647)
\end{aligned}
$$

\subsection{Light stage efficiency of photosynthesis}

Photosynthetic activities are affected by numerous abiotic and biotic stress factors. However, until recently, most studies on bean photosynthesis under environment stresses focused on abiotic stresses. In contrast, only a few studies have investigated the relationship between bean photosynthesis and biotic stresses.

For the measurement of the light stage efficiency of photosynthesis, an indirect chlorophyll fluorescence induction method was used (SCHEIBER et al., 1996). The in vivo fluorescence, the parameters of the quick phase of chlorophyll fluorescence induction, was measured in dark adapted leaves, using a PAM-2001 type fluorometer (Walz Gmbh, Germany). Before the measurements, the sample leaves were adapted to the dark by covering it for $20 \mathrm{~min}$. During measurement the dark-adapted sample leaves were illuminated with a weak light beam, obtaining the basic fluorescence level $\left(\mathrm{F}_{0}\right)$. Then a saturating light impulse $\left(6000 \mu \mathrm{mol} \mathrm{m} \mathrm{m}^{-2} \mathrm{~s}^{-1}\right)$ was applied to obtain the maximal fluorescence $\left(\mathrm{F}_{\mathrm{m}}\right)$. The difference between the $F_{m}$ and the $F_{0}$ value is the variable fluorescence $\left(F_{v}\right)$. The $F_{v} / F_{m}$ rate is used for the description of the maximal photochemical activity of PSII system, which refers to the light stage efficiency of the photosynthesis.

\subsection{Enzyme assays}

In the experiment, the activity of two important enzymes related to the reactive oxygen species, the activity of superoxide-dismutase (SOD), and the rate of lipid peroxidation (LP) were measured. Firstly, the activity of superoxide-dismutase was obtained by measuring the inhibition of the photochemical reduction of the nitroblue-tetrazolium (NBT) (GIANNopolitis \& Ries, 1977; BEYER \& Fridovich, 1987). One unit of SOD is defined as the quantity of the enzyme required to reach $50 \%$ decrease of the NBT's reduction measured at $560 \mathrm{~nm}$. The rate of lipid peroxidation was measured with the quantity of malondialdehyde (MDA) generated in the chemical assay by using the method of НеAтH and PACKER (1968). 


\subsection{Statistical analysis}

For the statistical analysis of the results, $t$-test was carried out with Sigma Plot 12.0 program.

\section{Results and discussion}

\subsection{Relative chlorophyll content}

Dry matter production, and consequently crop yield, is largely determined by the amount of solar radiation intercepted by the green leaf area and by radiation utilisation efficiency. Thus, photosynthesis is the key physiological process to understand crop yield potential and how this potential can be affected by various stresses. Most stress factors impact photosynthesis, even if they do not affect the composition of the photosynthetic apparatus directly (LichtenthaleR, 1996).

Consequently, the changes in the relative chlorophyll content of the plants were measured after seven and 14 days of inoculation with bean-rust (Table 1). When bean plants were inoculated, the relative chlorophyll content was significantly lower in both samplings. The relative chlorophyll content was reduced by $14 \%$ (6 SPAD-units) after one week and by $41 \%$ (14 SPAD-Units) two weeks after inoculation.

Table 1. Changes in relative chlorophyll content with bean rust infection (SPAD-Units)

\begin{tabular}{lll}
\hline & $1^{\text {st }}$ sampling & $2^{\text {nd }}$ sampling \\
\hline Control & $43.96 \pm 4.13$ & $34.66 \pm 7.02$ \\
Bean rust infected & $37.93 \pm 6.06^{*}$ & $20.55 \pm 8.07^{* * *}$ \\
\hline
\end{tabular}

1. sampling: 1 week after inoculation; 2. sampling: 2 weeks after inoculation. $N=10 \pm$ S.D., Significant difference compared to control: *: $\mathrm{P}<0.05, * * *: \mathrm{P}<0.001$

\subsection{Quantification of photosynthetic pigments}

As relative chlorophyll content is only a relative value, the amount of photosynthetic pigments (chlorophyll- $a$, chlorophyll- $b$, carotenoids) was also measured in the primary leaves. As indicated in Table 2, the amount of each measured photosynthetic pigment was significantly lower due to rust infection. The chlorophyll- $a$ concentration was significantly reduced by $33 \%$, while the contents of chlorophyll- $b$ and carotenoids were reduced by $34 \%$ after one week of treatment of the primary leaves with bean rust. The effect of bean infection was by far the highest two weeks after the inoculation, with $60 \%$ reduction in chlorophyll- $a, 57 \%$ reduction in chlorophyll- $b$, and $40 \%$ in carotenoids contents.

\subsection{Light stage efficiency of photosynthesis}

Very few generalizations can be made regarding the ways pathogens affect photosynthesis. In most host-pathogen interactions, both net and gross photosynthetic rate decline, respiration rate increases, and chlorophyll is lost from the tissue as infection progresses (SCHOLES, 1992). 
Table 2. Changes in the amount of photosynthetic pigments with bean rust infection $\left(\mathrm{mg} \mathrm{g}^{-1}\right)$

\begin{tabular}{llll}
\hline & Chlorophyll- $a$ & Chlorophyll- $b$ & Carotenoids \\
\hline \multicolumn{1}{c}{$1^{\text {st }}$ sampling } & \\
\hline Control & $9.12 \pm 1.61$ & $3.42 \pm 0.58$ & $6.88 \pm 1.05$ \\
Bean rust infected & $6.16 \pm 1.20^{*}$ & $2.24 \pm 0.79^{*}$ & $4.52 \pm 0.79^{*}$ \\
\hline \multicolumn{2}{c}{$2^{\text {nd }}$ sampling } & \\
\hline Control & $5.57 \pm 0.55$ & $1.93 \pm 0.48$ & $4.41 \pm 0.62$ \\
Bean rust infected & $2.23 \pm 1.17^{* *}$ & $0.83 \pm 0.57^{*}$ & $2.65 \pm 0.94^{* *}$ \\
\hline
\end{tabular}

1. sampling: one week after inoculation, 2 . sampling: two weeks after inoculation. $\mathrm{N}=5 \pm$ S.D., Significant difference compared to control: *: $\mathrm{P}<0.05$, **: $\mathrm{P}<0.01$

Over the last decade, chlorophyll fluorescence, obtained in vivo with a fluorometer, has been known as the "plant physiologist's stethoscope", as it measures the efficiency of the photosynthetic activity. Thus, the fluorometer can provide approximate estimates of the vitality and vigour of a plant in its environment (HALL \& RAO, 1994).

Several studies have investigated the effect of bean rust on photosynthetic activity (Livne, 1964). Based on LivnE's (1964) research, the photosynthetic activity decreased when bean was inoculated with rust. In the current study, photosynthetic activity did not change significantly one week after rust inoculation (Table 1). The value of maximum fluorescence $\left(\mathrm{F}_{\mathrm{m}}\right)$ and $\mathrm{F}_{\mathrm{v}} / \mathrm{F}_{\mathrm{m}}$ value were also significantly reduced two weeks after bean rust inoculation. However, Moll and co-workers (1995) reported that $\mathrm{F}_{\mathrm{o}}, \mathrm{F}_{\mathrm{m}}$, and $\mathrm{F}_{\mathrm{v}} / \mathrm{F}_{\mathrm{m}}$ ratio were not influenced by bean rust infection. Furthermore, no correlations between $\mathrm{F}_{\mathrm{o}}$ and severity of bean rust were found, but the $\mathrm{F}_{\mathrm{m}}$ value significantly decreased. Similarly, CHEN and coworkers (2015) reported that no effect on photosynthetic activity was evident when wheat was inoculated with rust.

Table 3. Changes in the light stage efficiency of photosynthesis with bean rust infection

\begin{tabular}{llll}
\hline \multicolumn{1}{c}{$\mathrm{F}_{0}$} & $\mathrm{~F}_{\mathrm{m}}$ & $\mathrm{F}_{\mathrm{v}} / \mathrm{F}_{\mathrm{m}}$ \\
\hline \multicolumn{2}{c}{$1^{\text {st }}$ sampling } & \\
\hline Control & $0.271 \pm 0.025$ & $1.698 \pm 0.062$ & $0.770 \pm 0.021$ \\
Bean rust infected & $0.273 \pm 0.024$ & $1.563 \pm 0.122$ & $0.785 \pm 0.012$ \\
\hline \multicolumn{2}{c}{$2^{\text {nd }}$ sampling } & \\
\hline Control & $0.272 \pm 0.043$ & $1.827 \pm 0.124$ & $0.844 \pm 0.008$ \\
Bean rust infected & $0.259 \pm 0.024$ & $1.511 \pm 0.305^{*}$ & $0.803 \pm 0.014^{*}$ \\
\hline
\end{tabular}

1. sampling: one week after inoculation; 2. sampling: two weeks after inoculation. $\mathrm{N}=10 \pm$ S.D., Significant difference compared to control: *: $\mathrm{P}<0.05$

\subsection{Enzyme assays}

2.4.1. Activity of superoxide-dismutase. A rapid increase in reactive oxygen species (ROS) concentration, known as the oxidative burst, is one of the earliest defence responses in many plant-pathogen interactions (APOSTOL et al., 1989). Elevated levels of ROS such as superoxide 
anion $\left(\mathrm{O}^{2-}\right)$, hydrogen peroxide $\left(\mathrm{H}_{2} \mathrm{O}_{2}\right)$, and hydroxyl radical $\left(\mathrm{OH}^{*}\right)$ are produced in plants by various oxidases and peroxidases. The superoxide anion produced, serves as starting material for the production of a variety of reactive oxidants. During plant-pathogen interactions the defence response is often associated with induced superoxide-dismutase activity and hence the accumulation of hydrogen peroxide.

The effect of rust infection was not significant on SOD activity in the present study.

\begin{tabular}{lcc}
\multicolumn{2}{c}{ Table 4. Changes in SOD activity with bean rust infection $(\mathrm{U} / \mathrm{g}$ FW) } \\
\hline & $1^{\text {st }}$ sampling & $2^{\text {nd }}$ sampling \\
\hline Control & $0.09 \pm 0.00$ & $0.04 \pm 0.00$ \\
Bean rust infected & $0.10 \pm 0.01$ & $0.06 \pm 0.01$ \\
\hline
\end{tabular}

1. sampling: one week after inoculation; 2. sampling: two weeks after inoculation. $\mathrm{N}=5 \pm$ S.D.

2.4.2. Rate of lipid peroxidation. The amount of MDA is significantly increased (14.03 nmol) one week after bean rust infection.

No changes could be observed after two weeks of inoculation. Only a few studies examined the effect of fungal infection on lipid peroxidation. GEORGIOU (1997) reported that the Sclerotial initials showed 100-fold increase in lipid peroxidation of their total lipids when compared to young mycelia grown under reducing conditions. In addition, a relationship between the number of Sclerotia formed and lipid peroxidation levels was also noted (Georgiou, 1997).

Table 5. Changes in LP activity with bean rust infection (nmol MDA/g FW)

\begin{tabular}{llc}
\hline & $1^{\text {st }}$ sampling & $2^{\text {nd }}$ sampling \\
\hline Control & $62.75 \pm 4.62$ & $79.04 \pm 7.39$ \\
Bean rust infected & $76.78 \pm 9.18^{*}$ & $82.11 \pm 10.75$ \\
\hline
\end{tabular}

1. sampling: one week after inoculation; 2 . sampling: two weeks after inoculation. $N=5 \pm$ S.D. Significant difference compared to control: $* \mathrm{P}<0.05$

\section{Conclusions}

The results indicate that the length of the time after inoculation primarily affects not only the activity of superoxide dismutase enzyme, but the rate of lipid peroxidation and also the amount of photosynthetic pigments in addition to photosynthetic efficiency in the infected bean leaves. The differences noted in the data at the first and the second sampling can be explained by the life cycle of the pathogen.

\footnotetext{
$\Rightarrow$ This research was supported by the ÚNKP-17-2 New National Excellence Program of the Ministry of Human Capacities.
} 


\section{References}

Agrios, G.N. (2005): Plant pathology, $5^{\text {th }}$ ed. Academic Press, San Diego, California, 952 pages.

Apostol, I., Heinstein, P.F. \& Low, P.S. (1989): Rapid stimulation of an oxidative burst during elicitation of cultured plant cell. Plant Physiol., 90, 109-116.

Barna, B., Fodor, J., Harrach, B.D., Pogány, M. \& Király, Z. (2012): The Janus facet of reactive oxygen species in resistance and susceptibility of plants to necrotrophic and biotrophic pathogens. Plant Physiol. Bioch., 59, $37-43$.

Beyer, W.F. \& Fridovich, I. (1987): Assaying for superoxide dismutase activity: some large consequences of minor changes in conditions. Anal. Biochem., 161, 559-566.

Broughton, W.J., Hernandez, G., Blair, M., Beebe, S., Gepts, P. \& Vanderleyden, J. (2003): Beans (Phaseolus spp.) - model food legumes. Plant Soil, 252, 55-128.

Chen, Y.E., Cui, J.M., Su, Y.Q., Yuan, S., Yuan, M. \& Zhang, H.Y. (2015): Influence of stripe rust infection on the photosynthetic characteristics and antioxidant system of susceptible and resistant wheat cultivars at the adult plant stage. Front. Plant Sci., 6, 779.

Foyer, C.H. \& Noctor, G. (2003): Redox sensing and signalling associated with reactive oxygen in chloroplasts, peroxisomes and mitochondria. Physiol. Plantarum, 119, 355-364.

Georgiou, C.D. (1997): Lipid peroxidation in Sclerotium rolfsii: A new look into the mechanisms of sclerotial biogenesis in fungi. Mycol. Res., 101(4), 460-464.

Giannopolitis, C.H. \& Ries, S.K. (1977): Superoxide dismutase. I. Occurrence in higher plant. Plant Physiol., 59, 309-314.

Hall, D.O. \& Rao, K.K. (1994): Photosynthesis. Cambridge University Press, Cambridge, 211 pages.

Heath, R.L. \& Packer, L. (1968): Photoperoxidation in isolated chloroplasts. I. Kinetics and stoichiometry of fatty acid peroxidation. Arch. Biochem. Biophys., 125, 189-198.

Lichtenthaler, H.K. (1996): Vegetation stress: An introduction to the stress concept in plants. J. Plant Physiol., 148(1-2), 4-14

Livne, A. (1964): Photosynthesis in healthy and rust-affected plants. Plant Physiol., 39, 614-621.

McMillan, M.S., Schwartz, H.M. \& Otto, K.I. (2003): Sexual stage development of Uromyces appendiculatus and its potential use for disease resistance screening in Phaseolus vulgaris. Plant Dis., 87, 1133-1138.

Mersha, Z. \& Hau, B. (2011): Reciprocal effects of host and disease dynamics in the bean rust pathosystem, J. Plant Dis. Protect., 118(2), 54-62.

Mmbaga, M.T., Steadman, J.R. \& Stavely, J.R. (1996): The use of host resistance in disease management of rust in common bean. Integrated Pest Management Reviews, 1, 191-200.

Moll, S., Serrano, P. \& Boyle, C. (1995): In vivo chlorophyll fluorescence in rust-infected bean plants. Angew. Bot., 69, 163-168.

Moran, R. \& Porath, D. (1980): Chlorophyll determination in intact tissues using N,N-dimethylformamide. Plant Physiol., 65, 478-479.

Scheiber, U., Kühl, M., Kliment, I. \& Reising, H. (1996): Measurement of chlorophyll fluorescence within leaves using a modified PAM fluorometer with a fiber-optic microprobe. Phytosynth. Res., 47, 103-109.

Shetty, N.P., Jorgensen, H.J.L., Jensen, J.D., Collinge, D.B. \& Shetty, H.S. (2008): Roles of reactive oxygen species in interactions between plants and pathogens. Eur. J. Plant Pathol., 121, 267-280.

Scholes, J.D. (1992): Plant responses to foliar attach. Photosynthesis: Cellular and tissue aspects in diseased leaves -in: Ayres, P.G. (Ed.), Plant and pathogens. BIOS Scientific Publisher, Oxford, UK, pp. 85-105.

Stavely, J.R. \& Pastor-Corrales, M.A. (1989): Rust. -in: Schwartz, H.F. \& Pastor-Corrales, M.A. (Eds), Bean production problems in the tropics $\left(2^{\text {nd }}\right.$ ed.), Centro Internacional de Agricultura Tropical Press, Cali, pp. 159-194.

Suzuki, N. \& Mittler, R. (2006): Reactive oxygen species and temperature stresses: A delicate balance between signaling and destruction. Physiol. Plant, 126, 45-51.

Udding, J., Gelang-Alfredsson, J., Piikki, K. \& Pleijel, H. (2007): Evaluating the relationship between leaf chlorophyll concentration and Spad-502 chlorophyll meter readings. Photosynth. Res., 91(1), 3746.

Wellburn, A.R. (1994): The spectral determination of chlorophylls a and b, as well as total carotenoids, using various solvents with spectrophotometers of different resolution. J. Plant Physiol., 144(3), 307-313.

Open Acces statement. This is an open-access article distributed under the terms of the Creative Commons Attribution 4.0 International License (https://creativecommons.org/licenses/by/4.0/), which permits unrestricted use, distribution, and reproduction in any medium, provided the original author and source are credited, a link to the CC License is provided, and changes - if any - are indicated. (SID_1) 